ADALAH : Buletin Hukum \&

Keadilan

Buletin Hukum \& Keadilan

@adalahuinjkt

\title{
Integritas Hakim Indonesia
}

Siti Nurhalimah*

Integritas dalam diri seorang hakim, merupakan salah satu kode etik dan perilaku hakim sedunia yang disepakati dalam The Bangalore Principles of Judicial Conduct (Konferensi Peradilan Internasional di Bangalore, India pada tahun 2001). Hal tersebut mutlak dimiliki seorang hakim sebagai kunci utama untuk membuka pintu-pintu keadilan bagi masyarakat sebagaimana yang dijanjikan UUD 1945. Namun saat ini, hakim Indonesia sedang dilanda krisis integritas. Terlihat dari banyaknya pelanggaran terhadap pedoman perilaku hakim, ditambah banyaknya deretan hakim yang tertangkap tangan terlibat kasus korupsi.

Mengapa krisis integritas ini terjadi? Para pakar hukum Indonesia yang menggelar pertemuan pada 24 Mei 2017 di Yogyakarta berkesimpulan bahwa, hal ini terjadi akibat tidak teraturnya manajemen hakim, mulai dari pola rekrutmen, pembinaan, pengawasan, hingga proses pemberhentian. Artinya, rentetan peraturan yang dianggap kurang baik tersebutlah yang telah mengikis

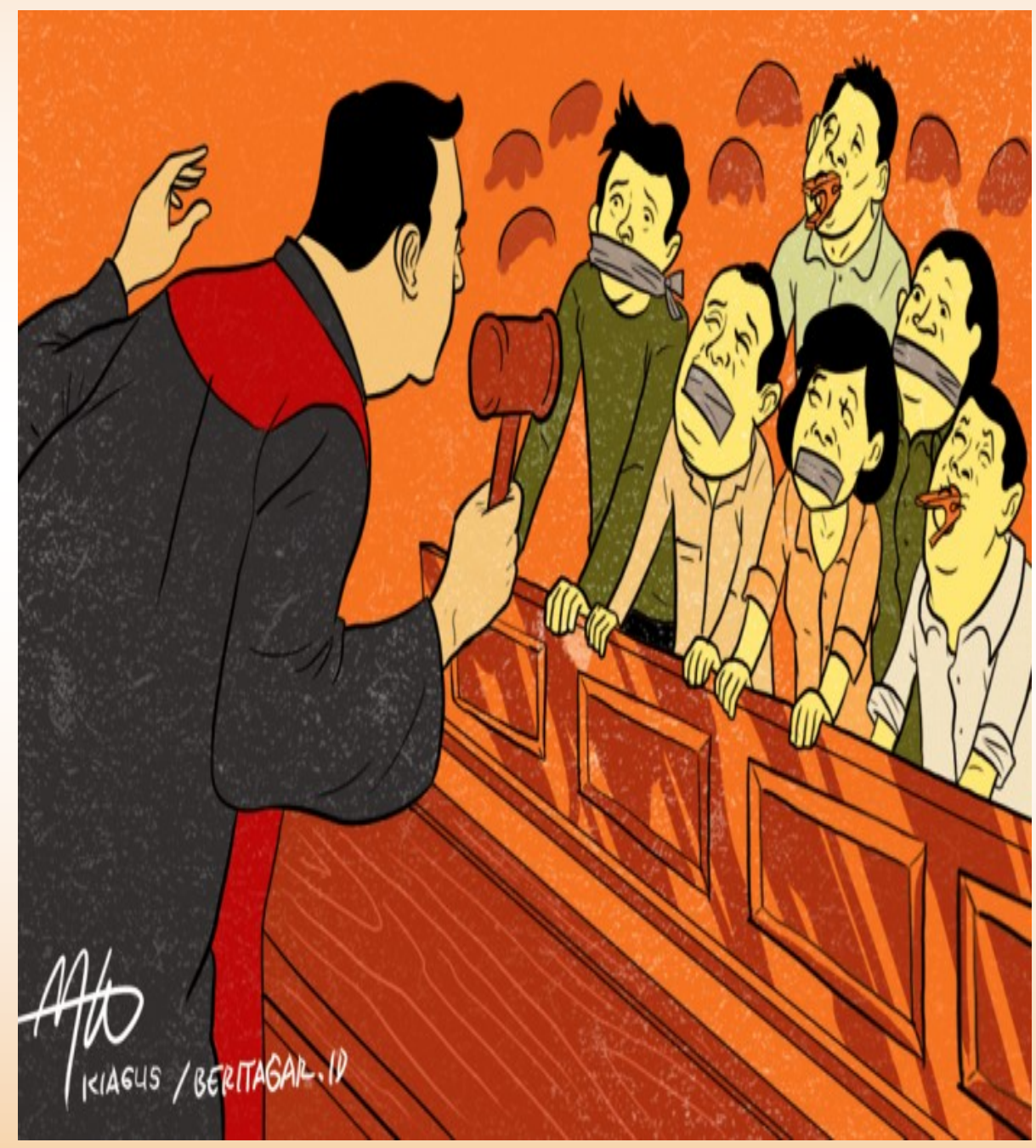

kualitas serta integritas hakim- Mulai dari hakim Pengadilan hakim yang telah ada, serta Negeri, Pengadilan Tinggi, memunculkan hakim-hakim baru Mahkamah Agung, bahkan hakim yang tidak mumpuni secara Mahkamah Konstitusi. Kasus hakim kredibilitas, kapabilitas, termasuk konstitusi Patrialis Akbar serta integritas.

Fenomena tercorengnya beberapa hakim yang tertangkap tangan menerima suap agar integritas hakim terjadi hampir mengeluarkan putusan sesuai pada semua tingkat pengadilan. kehendak pemberi suap. Hal ini 
mencerminkan betapa buruknya integritas hakimhakim Indonesia sampai-sampai putusan sang wakil Tuhan tersebut itu pun dapat ditukar dengan uang.

Karenanya, krisis integritas hakim Indonesia tidak dapat lagi dianggap sepele, melainkan telah memasuki tahap yang memprihatinkan. Tanpa integritas yang tinggi, seorang hakim akan memutus perkara tidak berdasarkan keadilan, sehingga masyarakat tidak tahu lagi kemana mereka akan mencari keadilan, sebagai cita-cita bersama yang termuat dalam konstitusi untuk membangun negara yang ideal (Baital, 2014 : 23).

Integritas hakim yang kian merosot, dibuktikan oleh laporan akhir tahun 2016 Komisi Yudisial. Dalam laporan Komisi Yudisial diungkapkan bahwa terdapat 1.682 laporan dan 1.899 surat tembusan laporan masyarakat terkait pelanggaran kode etik yang dilakukan oleh hakim-hakim Indonesia sepanjang tahun 2016. Jumlah data tersebut tidak jauh berbeda dengan data tahun-tahun sebelumnya. Dengan demikian, sejauh ini belum ada perbaikan secara signifikan atas perilaku sang penegak hukum negeri ini.

Tingginya jumlah pelanggaran kode etik serta deretan kasus korupsi hakim-hakim Indonesia yang tak kunjung surut dari tahun ke tahun, telah berhasil menimbulkan public distrust terhadap lembaga peradilan. Sebagai upaya memperbaiki marwah lembaga peradilan dalam melahirkan hakim-hakim yang berintegritas serta untuk menghilangkan stigma "krisis integritas" hakim yang telah menjadi sorotan publik, konsep "Shared Responsibility" atau pembagian peran Mahkamah Agung dan Komisi Yudisial dalam manajemen jabatan hakim perlu segera diterapkan. Sehingga, optimalisasi manajemen jabatan hakim yang selama ini hanya dilakukan oleh Mahkamah Agung dapat lebih terealisasi dengan bantuan Komisi Yudisial.

Dengan diterapkannya konsep "Shared Responsibility" antara MA dan KY, diharap dapat memperbaiki dan meningkatkan integritas para pemangku jabatan hakim sebagai benteng terakhir penegakan hukum di negara demokratis ini
(Maggalatung, 2014: 192), karena sejatinya, apabila integritas para hakim di negeri ini senantiasa terpelihara, masyarakat akan sangat mungkin selalu menggenggam keadilan. Sebaliknya, apabila integritas para hakim di negeri ini terus menurun dan tidak diperhatikan, maka mimpi masyarakat untuk menggenggam keadilan hanyalah laksana punuk merindukan bulan.[]

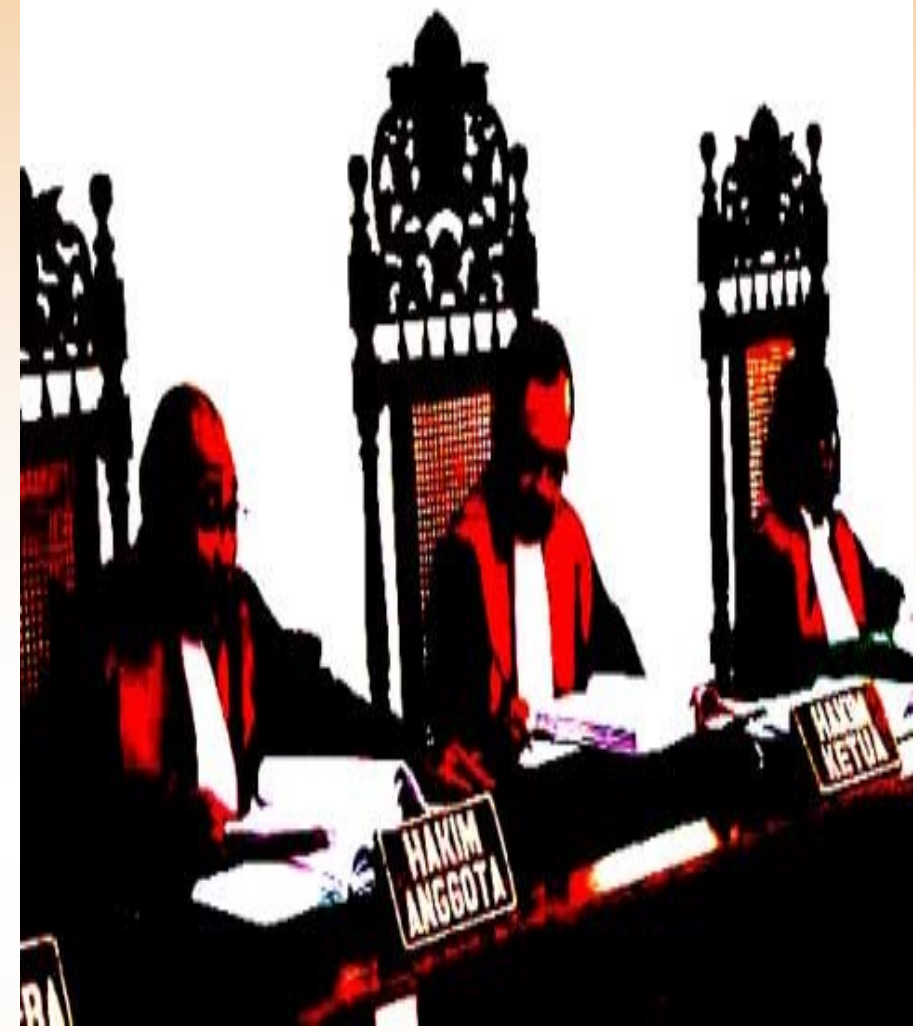

\section{Daftar Pustaka:}

*Penulis adalah anggota Perhimpunan Mahasiswa Hukum Indonesia (PERMAHI) dan Anggota Moot Court Community (MCC) FSH UIN Jakarta.

Baital, Bachtiar, 2014. “Pertanggungjawaban Penggunaan Hak Prerogatif Presiden Di Bidang Yudikatif Dalam Menjamin Kemerdekaan Kekuasaan Kehakiman," Jurnal Cita Hukum, Vol. 2, No. 1, Juni.

Maggalatung, Salman. 2014. Hubungan Antara Fakta Norma, Moral, Dan Doktrin Hukum Dalam Pertimbangan Putusan Hakim, Jurnal Cita Hukum, Vol. 2, No. 2, Desember.

'Adalah; Buletin Hukum dan Keadilan merupakan berkala ilmiah yang diterbitkan oleh Pusat Studi Konstitusi dan Legislasi Nasional (POSKO-LEGNAS), Fakultas Syariah dan Hukum UIN Syarif Hidayatullah Jakarta.

Penasehat: Prof. Dr. H. Abdul Ghani Abdullah, SH., Prof. Dr. H. A Salman Maggalatung, SH., MH. Pemimpin Redaktur: Indra Rahmatullah, Tim Redaktur: Nur Rohim Yunus, Fathuddin, Mara Sutan Rambe, Muhammad Ishar Helmi, Erwin Hikmatiar. Penyunting: Indah Furba, Hasin Abdullah. Setting \& Layout: Siti Anisaul Kamilah. 